\title{
Electronic Band Structures of $\mathrm{La}_{2 / 3} \mathrm{~Pb}_{1 / 3} \mathrm{Mn}_{2 / 3}(\mathrm{Fe}, \mathrm{Co}, \mathrm{Ni})_{1 / 3} \mathrm{O}_{3}$
}

\author{
M. KowaliK*, W. TokARz And A. KolodzIEJCZYK \\ Department of Solid State Physics, AGH University of Science and Technology, \\ al. A. Mickiewicza 30, 30-059 Kraków, Poland
}

\begin{abstract}
We present calculations of the electronic band structures of $\mathrm{La}_{2 / 3} \mathrm{~Pb}_{1 / 3} \mathrm{Mn}_{2 / 3}(\mathrm{Fe}, \mathrm{Co}, \mathrm{Ni})_{1 / 3} \mathrm{O}_{3}$ colossal magneto-resistance manganites. The calculations are based on first-principles density functional theory with general gradient approximation GGA $+\mathrm{U}$ using WIEN2k package. The calculations show that electronic structures of these compounds consist mainly of $\mathrm{Mn} 3 d, \mathrm{O} 2 p$, and $(\mathrm{Fe}, \mathrm{Co}, \mathrm{Ni}) 3 d$ states, which are hybridized over whole valence bands. Substitution $\mathrm{Mn}$ ion by Fe, Co, or Ni ions reduces the Mn and O contributions to the valence bands and weakens the double exchange interaction. The results are in good agreement with available experimental data.
\end{abstract}

DOI: 10.12693/APhysPolA.127.251

PACS: 71.20.-b, 71.55.Ak, 72.80.Ga, 75.47.Lx, 79.60.-i

\section{Introduction}

Manganites with general formula $\mathrm{REAMnO}_{3}$, where $\mathrm{RE}$ are trivalent rare earth ions ( $\mathrm{La}, \mathrm{Pr}, \mathrm{Nd}, \mathrm{Sm})$ and $\mathrm{A}$ are divalent alkaline earth ions $(\mathrm{Ca}, \mathrm{Sr}, \mathrm{Ba}, \mathrm{Pb})$, exhibit a large variety of electric and magnetic properties due to complex interplay between charge and orbital degree of freedom of the mixed-valence Mn cations and the doubleexchange (DE) interaction modified by Jahn-Teller distortion interaction and tilting of $\mathrm{Mn}-\mathrm{O}_{6}$ octahedrals [1]. Ferromagnetic (FM) ordering in $\mathrm{REAMnO}_{3}$ has been attributed to the $\mathrm{DE}$ interaction between the valence electron state of $\mathrm{Mn}^{3+}-\mathrm{O}^{2-}-\mathrm{Mn}^{4+}[2-5]$. The FM state with a large spin splitting of the conduction band into majority and minority sub-bands separated by the on-site Hund interaction is a consequence of DE interaction and lattice distortion [6].

The transport and magnetic properties of REAMnTMO $_{3}$ manganites, where TM is a transition metal, are known to be strongly dependent upon changes in the strength of the DE interaction, which can be altered by the substitution of the trivalent RE ions by divalent $\mathrm{A}$ ions and also $\mathrm{Mn}$ ions by the other TM ions e.g. $\mathrm{Fe}, \mathrm{Co}, \mathrm{Ni}[7-10]$. The composition $\mathrm{La}_{0.7} \mathrm{~Pb}_{0.3} \mathrm{MnO}_{3}$ corresponding to a $\mathrm{Mn}^{3+} / \mathrm{Mn}^{4+}$ ratio that maximizes the DE interaction, shows ferromagnetism and raises magnetic ordering temperature $T_{\mathrm{C}}[9,10]$. From experimental studies at low temperatures it is known that $\mathrm{Fe}$, $\mathrm{Co}$ and $\mathrm{Ni}$ ions enter into the $\mathrm{La}_{0.7} \mathrm{~Pb}_{0.3} \mathrm{Mn}_{0.7} \mathrm{TM}_{0.3} \mathrm{O}_{3}$ as high-spin $\mathrm{Fe}^{3+}$, as diamagnetic low-spin $\mathrm{Co}^{3+}$ and as low spin $\mathrm{Ni}^{3+}$, respectively. Fe ions couple antiferromagnetically with $\mathrm{Mn}$ ions, on the contrary to $\mathrm{Ni}$ ions, which are coupled ferromagnetically $[9,10]$.

All considered TM substitutions weaken DE interaction and lead to decrease in both magnetic ordering temperatures $T_{\mathrm{C}}$ and low-temperature magnetic moments.

\footnotetext{
*corresponding author; e-mail: mkowalik@agh.edu.pl
}

These changes soar with increasing TM content. Substitution level up to only $30 \%$ generates low distortion in the crystal structure of these compounds [7-10].

In this work we present results of theoretical $a b$ initio band structure calculations for the $\mathrm{La}_{2 / 3} \mathrm{~Pb}_{1 / 3} \mathrm{Mn}_{2 / 3}(\mathrm{Co}, \mathrm{Fe}, \mathrm{Ni})_{1 / 3} \mathrm{O}_{3}$ manganites in $P \overline{3} c 1$ crystal structure.

\section{Computational details}

The calculations were done in the WIEN2k code (version 11.1) [11] based on the density functional theory (DFT) $[12,13]$ and the generalized gradient approximation (GGA) $[14,15]$. For the $3 d \mathrm{Mn}, \mathrm{Fe}$, Co and $\mathrm{Ni}$ electrons the Hartree-Fock-like exchange energy was included in hybrid functional with $\alpha=0.25$ fraction $[16,17]$. The spin-orbit interaction is planned to be included into calculation. The optimal $k$ point number was examined by calculating total energy as the function of the number of $k$-points. As a result $202 k$ points in irreducible Brillouin zone was chosen. The self-consistent calculations were continued until a charge convergence was better than $0.001 \mathrm{e}$. The density of states (DOS) was calculated using the modified tetrahedron method [18].

The X-ray powder analysis of compounds with similar substitution showed rhombohedral crystal structure $R \overline{3} c$, i.e. no. 167 according to the International Tables for Crystallography (ITC) [7-10, 19]. In our calculations the $P \overline{3} c 1$ (i.e. no. 165 according to ITC) crystal structure was chosen (Fig. 1) in order to achieve proper substitution of La ions by $\mathrm{Pb}$ ions and $\mathrm{Mn}$ ions by $\mathrm{Fe}$, $\mathrm{Co}$ or Ni ions. The detailed description of crystal structure determination and its structure optimization, which is required to fair electronic band structure computation, can be found in our previous papers [20,21]. Computed lattice constants are $a=10.1685 a_{\mathrm{o}}, c=25.6286 a_{\mathrm{o}}$, $a=10.2988 a_{\mathrm{o}}, c=24.8973 a_{\mathrm{o}}$, and $a=10.3009 a_{\mathrm{o}}, c=$ $24.8921 a_{\mathrm{o}}$ for the $\mathrm{Fe}, \mathrm{Co}$, and Ni substituted compounds, respectively, and $a_{\mathrm{o}}$ is the Bohr radius. Atomic positions of $\mathrm{Pb}$ and $\mathrm{TM}$ ions are $(0,0,1 / 4)$ and $(0,0,0)$, respectively. They do not vary with TM ion. Other atomic 
positions for Fe substituted manganite are La $(1 / 3,2 / 3$, $0.9165)$, Mn (1/3, 2/3, 0.6662), O(1) (0.5293, 0, 1/4) and $\mathrm{O}(2)(0.8763,0.6595,0.9200)$. Other atomic positions for Co substituted manganite are La $(1 / 3,2 / 3$, 0.9158), Mn (1/3, 2/3, 0.6651), O(1) (0.5318, 0, 1/4) and $\mathrm{O}(2)(0.8736,0.6579,0.9205)$. Other atomic positions for $\mathrm{Ni}$ substituted manganite are $\mathrm{La}(1 / 3,2 / 3$, $0.9167), \mathrm{Mn}(1 / 3,2 / 3,0.6653), \mathrm{O}(1)(0.5353,0,1 / 4)$ and $\mathrm{O}(2)(0.8705,0.6476,0.9178)$. The results presented in the next paragraph were calculated based on these crystal settings.

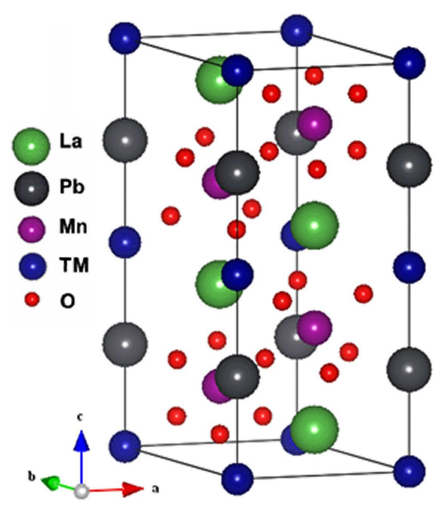

Fig. 1. Unit cell of $\mathrm{La}_{2 / 3} \mathrm{~Pb}_{1 / 3} \mathrm{Mn}_{2 / 3}(\mathrm{Fe}, \mathrm{Co}, \mathrm{Ni})_{1 / 3} \mathrm{O}_{3}$.

Considering the results of magnetic measurements of $\mathrm{La}_{0.7} \mathrm{~Pb}_{0.3} \mathrm{Mn}_{0.7}(\mathrm{Fe}, \mathrm{Co}, \mathrm{Ni})_{0.3} \mathrm{O}_{3}$ manganites $[7-10]$ and strong dependence of electronic band structure calculation in WIEN2k code [21] on the configuration of magnetic moments at ions, the initial moment at Co ions was set to zero in $\mathrm{La}_{2 / 3} \mathrm{~Pb}_{1 / 3} \mathrm{Mn}_{2 / 3} \mathrm{Co}_{1 / 3} \mathrm{O}_{3}$, parallel configuration of magnetic moments on $\mathrm{Mn}$ and $\mathrm{Ni}$ ions and antiparallel configuration on $\mathrm{Mn}$ and Fe ions were set for the Ni- and Fe-substitutions, respectively.

\section{Results and their analysis}

To investigate the changes of the DE interaction triggered off by the substitution of manganese ions by other TM ions, the $a b$ initio electronic band structure calculations for the $\mathrm{La}_{2 / 3} \mathrm{~Pb}_{1 / 3} \mathrm{Mn}_{2 / 3}(\mathrm{Fe}, \mathrm{Co}, \mathrm{Ni})_{1 / 3} \mathrm{O}_{3}$ manganite in $P \overline{3} c 1$ crystal structure were undertaken.

The calculated total densities of states (DOS) and the local contributions from the particular atoms are presented in Fig. 2. The main contributions to the valence band (VB) come from Mn $3 d$ and O $2 p$ electronic states. Contributions from TM $3 d$ states and La, $\mathrm{Pb}$ states are minor and irrelevant. In contrary to oxygen ion the contribution of $\mathrm{Mn}$ ion to the $\mathrm{VB}$ and conduction band is mostly by majority subband. In case of $\mathrm{Fe}$ and $\mathrm{Ni}$ ions the corresponding contributions are mostly by minority and majority subbands, respectively. For the diamagnetic Co the contributions from majority and minority subbands are similar.

In comparison to unsubstituted $\mathrm{La}_{2} / 3 \mathrm{~Pb}_{1 / 3} \mathrm{MnO}_{3}$ [20] the $\mathrm{Mn}$ and $\mathrm{O}$ contributions to the $\mathrm{VB}$ are

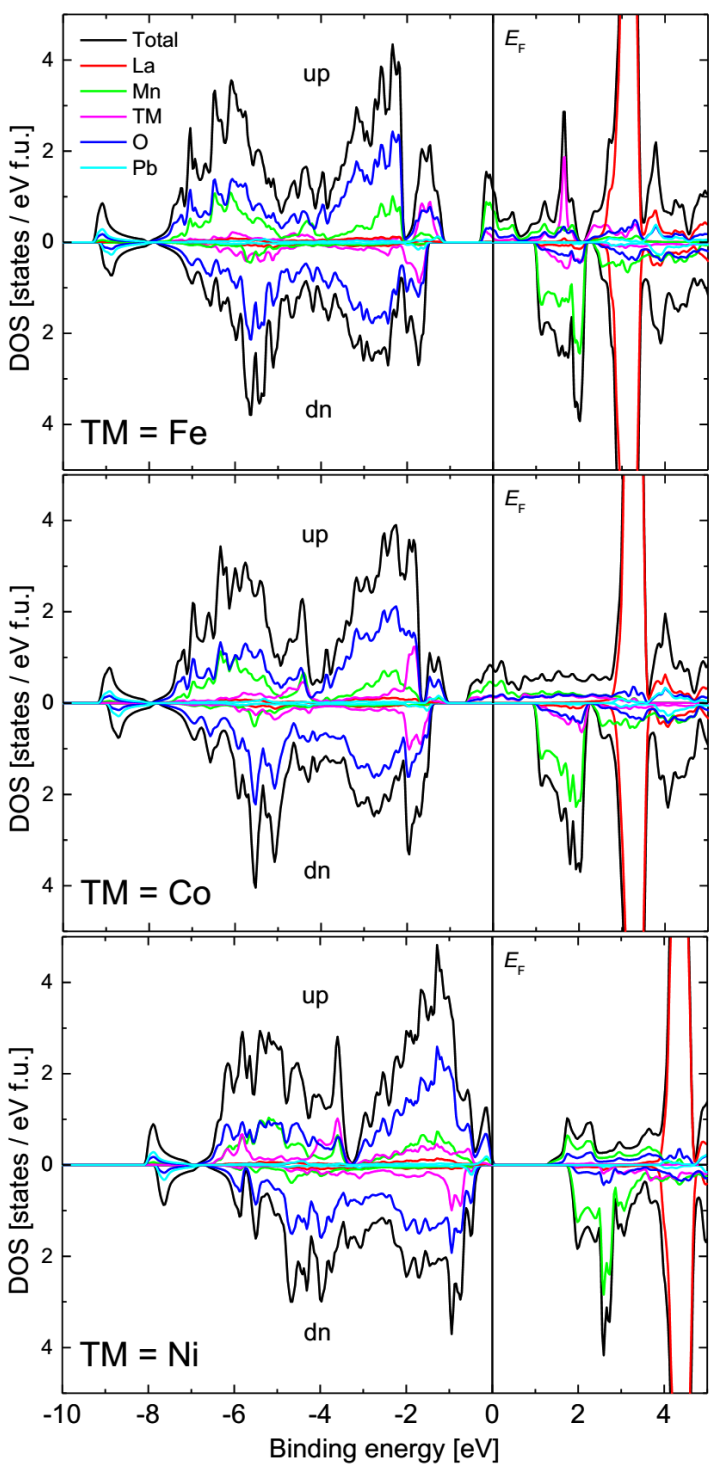

Fig. 2. Total calculated partial DOS for $\mathrm{La}_{2 / 3} \mathrm{~Pb}_{1 / 3} \mathrm{Mn}_{2 / 3} \mathrm{TM}_{1 / 3} \mathrm{O}_{3}$.

smaller, which results in weaker DE interaction in $\mathrm{La}_{2 / 3} \mathrm{~Pb}_{1 / 3} \mathrm{Mn}_{2 / 3}(\mathrm{Co}, \mathrm{Fe}, \mathrm{Ni})_{1 / 3} \mathrm{O}_{3}$ family of compounds. This result agrees well with magnetic experimental and transport data $[7-10]$.

The calculated DOS for the Fe and Co substituted compounds have half-metallic character and insulating character for Ni substitution. In the last case the DOS is dominated by oxygen states revealing the charge transfer like insulating character. The Fermi level lies close to a gap in the majority band. This gap is shifted below $E_{\mathrm{F}}$ for $\mathrm{Fe}$ and Co substitution, whilst above $E_{\mathrm{F}}$ for $\mathrm{Ni}$. Contrary to $\mathrm{Fe}$ ion, the $\mathrm{Co}$ and $\mathrm{Ni}$ ions introduce to the VB one and two electrons, respectively. This results in shifting $E_{\mathrm{F}}$ to the lower binding energy. The small electron pocket is present for majority band for $\mathrm{Fe}$ and $\mathrm{Co}$ substitutions. 
The calculated magnetic moments for $\mathrm{Fe}, \mathrm{Co}$ and $\mathrm{Ni}$ substitutions are $2.00 \mu_{\mathrm{B}} /$ f.u., $2.33 \mu_{\mathrm{B}} /$ f.u. and $2.67 \mu_{\mathrm{B}} /$ f.u., respectively, close to the experimental ones $[7-10]$.

The examples of calculated valence band ultraviolet photoemission $\mathrm{Ni}$ - and $\mathrm{Co}-$ substituted spectra are shown in Fig. 3. The calculated spectrum for the case of $\mathrm{Fe}$ is quite similar to that of Co. The theoretical spectrum was calculated taking into account the partial electronic densities of states weighted with atomic photoemission cross-section [22] for the $\mathrm{He}(\mathrm{I})$ photon energy $21.2 \mathrm{eV}$ and the experimental energy resolution was taken as the energy-dependent Lorentzian function with a half-width of about $0.3 \mathrm{eV}$.

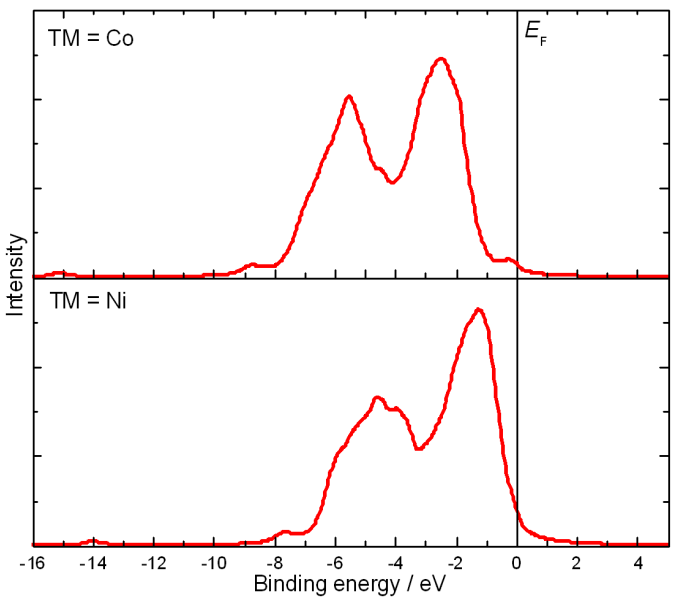

Fig. 3. Calculated UPS spectra of $\mathrm{La}_{2 / 3} \mathrm{~Pb}_{1 / 3} \mathrm{Mn}_{2 / 3} \mathrm{TM}_{1 / 3} \mathrm{O}_{3}$.

\section{Conclusions}

We have computed the electronic band structures of $\mathrm{La}_{2 / 3} \mathrm{~Pb}_{1 / 3} \mathrm{Mn}_{2 / 3}(\mathrm{Fe}, \mathrm{Co}, \mathrm{Ni})_{1 / 3} \mathrm{O}_{3}$ compounds for energy optimized $P \overline{3} c 1$ crystal structure. Initial magnetic moments configurations at $3 d$ ions, based on experimental data, give half-metallic DOS for Fe- and Co-substitutions and insulating DOS for Ni substitution. These DOS consist mainly of $\mathrm{Mn}, \mathrm{Fe}, \mathrm{Co}, \mathrm{Ni} 3 d$ and $\mathrm{O} 2 p$ states, which are hybridized over the whole valence bands.

The substitution of $\mathrm{Mn}$ ions by TM ions reduces the $\mathrm{Mn}$ and $\mathrm{O}$ contributions to the $\mathrm{VB}$ which weaken the $\mathrm{DE}$ interactions in $\mathrm{La}_{2 / 3} \mathrm{~Pb}_{1 / 3} \mathrm{Mn}_{2 / 3}(\mathrm{Fe}, \mathrm{Co}, \mathrm{Ni})_{1 / 3} \mathrm{O}_{3}$ manganites.

Substitution of Mn ions by $\mathrm{Co}$ or $\mathrm{Ni}$ ions increases the number of $3 d$ electrons in $\mathrm{VB}$ and shifts the Fermi level toward lower binding energy. According to the electronic band structure calculations a shifting of $E_{\mathrm{F}}$ should be seen in photoemission spectrometry measurements.

The calculated total magnetic moments for $\mathrm{Fe}, \mathrm{Co}$ and $\mathrm{Ni}$ substitutions are $2.00 \mu_{\mathrm{B}}$ /f.u., $2.33 \mu_{\mathrm{B}} /$ f.u. and $2.67 \mu_{\mathrm{B}}$ /f.u., respectively. These results are in good agreement with experimental data.

\section{Acknowledgments}

The paper has been financially supported by the Polish Ministry of Science and Higher Education and its grants for Scientific Research.

\section{References}

[1] E. Dagotto, Nanoscale Phase Separation and Colossal Magnetoresistance, Springer, Berlin 2002.

[2] C. Zener, Phys. Rev. 82, 403 (1951).

[3] P.W. Anderson, H. Hasegawa, Phys. Rev. 100, 675 (1955).

[4] J. Goodenough, Phys. Rev. 100, 564 (1955).

[5] P.G. de Gennes, Phys. Rev. 118, 141 (1960).

[6] P.G. de Gennes, J. Friedel, J. Phys. Chem. Solids 41, 71 (1958).

[7] J. Gutiérrez, A. Peña, J.M. Barandiarán, J.L. Pizarro, T. Hernández, L. Lezama, M. Insausti, T. Rojo, Phys. Rev. B 61, 9028 (2000).

[8] J. Gutiérrez, A. Peña, J.M. Barandiarán, J.L. Pizarro, L. Lezama, M. Insausti, T. Rojo, J. Phys. Condens. Matter 12, 10523 (2000).

[9] A. Peña, J. Gutiérrez, I.G. de Muro, J. Campo, J.M. Barandiarán, T. Rojo, Eur. J. Inorg. Chem. 2006, 3227 (2006).

[10] A. Peña, J. Gutiérrez, J. Campo, J.M. Barandiarán, L. Lezama, I.G. de Muro, T. Rojo, Eur. J. Inorg. Chem. 2008, 2569 (2008).

[11] P. Blaha, K. Schwarz, G.K.H. Madsen, D. Kvasnicka, J. Luitz, WIEN2K: An Augmented Plane Wave and Local Orbitals Program for Calculating Crystal Properties, Vienna University of Technology, Vienna 2001.

[12] P. Hohenberg, W. Kohn, Phys. Rev. B 136, 864 (1964).

[13] W. Kohn, L.J. Sham, Phys. Rev. 140, 1133 (1965).

[14] J.P. Perdew, K. Burke, M. Ernzerhof, Phys. Rev. Lett. 77, 3865 (1996).

[15] J.P. Perdew, A. Ruzsinszky, G.I. Csonka, O.A. Vydrov, G.E. Scuseria, L.A. Constantin, X. Zhou, K. Burke, Phys. Rev. Lett. 100, 136406 (2008).

[16] S. Kümmel, L. Kronik, Rev. Mod. Phys. 80, 3 (2008).

[17] F. Tran, P. Blaha, K. Schwarz, P. Novák, Phys. Rev. B 74, 155108 (2006).

[18] P.E. Blöchl, O. Jepsen, O.K. Andersen, Phys. Rev. B 49, 16223 (1994).

[19] G. Gritzner, M. Koppe, K. Kellner, J. Przewoźnik, J. Chmist, A. Kołodziejczyk, K. Krop, Appl. Phys. A 81, 1491 (2005).

[20] W. Tokarz, M. Kowalik, R. Zalecki, A. Kołodziejczyk, Acta Phys. Pol. A 121, 1151 (2012).

[21] W. Tokarz, M. Kowalik, A. Kołodziejczyk, Acta Phys. Pol. A 121, 876 (2012).

[22] J.J. Yeh, I. Lindau, At. Data Nucl. Data Tables 32, 1 (1985). 